\title{
Deep processing of organic mass of finely dispersed coal waste
}

\author{
Vasilii Murko ${ }^{1,2^{*}}$, Marina Baranova ${ }^{3,4}$ and Irina Grishina ${ }^{4}$ \\ ${ }^{1}$ FSBEI HE “KuzSTU”, Kemerovo, Russia \\ ${ }^{2}$ FSBEI HE "SibSIU", Novokuznetsk, Russia \\ ${ }^{3}$ FSBEI HE, "Krasnoyarsk SAU”, Krasnoyarsk, Russia \\ ${ }^{4}$ FSAEI HE "SFU”, Krasnoyarsk, Russia
}

\begin{abstract}
The technological and technical possibility of deep processing of coal by its liquefaction using the methods of extreme mechanochemical and physical effects has been determined; recommendations have been developed for the applied use of the obtained materials in heat power engineering. The organic part of the solid mass of the prepared coal-oil suspension, which has turned into a relatively heavy organic liquid, can be used as a boiler or motor fuel, as well as a feedstock for the production of various hydrocarbon liquids. The resulting mixture of hydrocarbons can be subjected to rectification to obtain hydrocarbon fractions for the production of plastics, oil fractions and the entire spectrum of hydrocarbons for secondary use. The effective use of the above substances will make it possible to obtain not only economic, but also a significant environmental effect. The possibility of liquefying the organic mass of coal using decalin as a hydrogen donor is shown. It was found that the addition of $3 \%$ decalin improves the liquefaction process during cavitation treatment. Liquefaction of the organic mass of coal is accompanied by the splitting of the structures of macromolecules of organic substances of coal into aromatic fragments with a lower molecular weight. It should be noted that the developed technology will solve the problem of increasing the value of the final coal product, including by involving unused fine coal sludge into circulation.
\end{abstract}

\section{Introduction}

Currently, there are practically no industrial technologies for processing substandard coals and coal sludge. For example, a filter cake with a particle size of $0-1000$ microns with a content of a class of $0-100$ microns up to $90 \%$, a moisture content of $30-45 \%$ and an ash content of $23-62 \%$ is sent to the dump along with a large rock. As a result, the environment is significantly polluted and a significant share of processed coal is lost (up to 10-12\%). In addition, the circulating water is saturated with residual flocculants, which disrupt the technological process of coal enrichment [1-5]. A complex of research in the field of the mechanism of converting the organic mass of solid fuel into liquid products contributes to an increase in the range of chemical products and raw materials for their production based

\footnotetext{
*Corresponding author: sib eco@kuz.ru
} 
on liquefaction products, such as aromatic hydrocarbons, phenols, raw materials for the production of electrode coke and much more. Also, a new demanded energy product is obtained - a mixture of hydrocarbons similar to oil, which the same processing plants can use as flocculants. The resulting product can also be used as fuel for boilers. In principle, the process is a way to obtain synthetic oil from the waste of coal mining enterprises and coal processing factories [4-10].

The study of the possibility of using coal sludge to obtain various organic products, suitable as raw materials for the production of various commercial organic compounds, is stimulated by the current and expected future limited amount of hydrocarbons produced from oil. Various cyclic hydrocarbons used in the manufacture of a wide range of polymers, dyes and drugs can be obtained from coal. The results of studies on the catalytic hydrogenation of coal at low pressures and temperatures $\left(1.8-2 \mathrm{MPa}, 180-200^{\circ} \mathrm{C}\right)$ are known with the decomposition of its organic substances into products of lower molecular weight, i.e. relatively small aromatic moieties containing various functional groups. The obtained aromatic compounds are promising for the production of various commercial products listed above [11-12].

To solve the problems of using low-grade coals and utilizing waste from coal preparation, an organic mass liquefaction plant has been created. The paper presents the results of the completed studies and shows the prospects for solving the existing problem. Thus, the purpose of the work was to obtain initial data for creating a pilot sample of a technological complex.

Characteristics of raw materials

To investigate the possibility of deep transformation of the organic mass of coal using mechanical and chemical destruction in the cavitation plant, samples of finely dispersed coal-enrichment wastes were taken and used, namely the filter cake "PP named after S.M. Kirov". The results of technical and elemental analyzes are presented in Table 1.

Table 1. Characterisation of samples.

\begin{tabular}{|l|c|c|}
\hline \multicolumn{1}{|c|}{ Indicator } & Sample №1 & Sample №2 \\
\hline Total moisture, \% & 40,3 & 40,8 \\
\hline Ash content (on dry fuel state), \% & 32,8 & 48,4 \\
\hline $\begin{array}{l}\text { Volatile matter release (for dry ash-free state } \\
\text { of fuel), \% }\end{array}$ & 42,4 & 41,4 \\
\hline Total sulfur & 0,15 & 0,13 \\
(for dry fuel condition), \% & & \\
\hline Gross calorific value (on dry fuel state), MJ & 33,08 & 33,00 \\
\hline Net calorific value of working fuel, MJ & 11,8 & 8,7 \\
\hline Grain-size classification, mm & & 6,3 \\
$0,250-3,0:$ & 26,8 & 17,3 \\
$0,071-0,250$ & 68,7 & 76,4 \\
$-0,071$ & 100,0 & 100,0 \\
\hline
\end{tabular}

Analysis of the data in Table 1. showed that the moisture content of the filter cake samples submitted for research was consistently high, of the order of $40 \%$. The ash content of the filter cake depends on the quality of the raw material and varies within a narrow range of values ( $A^{d}=30.7 \% ; 26.8 \%$ ). Granulometric composition of the filter cake from the mine of "PP named after S.M. Kirov" included size classes up to $3.0 \mathrm{~mm}$. 


\subsection{Research methodology}

\subsubsection{Preparation of water-coal suspensions}

The obtained filter cake is actually a semi-finished product for obtaining coal-water suspensions, the production of which is the first stage in the process of deep processing of the organic mass of coal. During the studies, laboratory samples of suspended coal fuel were prepared from a mixture of filter cake and an aqueous solution of a reagent-plasticizer. Taking into account the initial size of the filter cake, a mixing or grinding chamber of periodic action of a universal vibration stand was used to prepare CWS samples. Dosing of the starting components was performed manually.

CWS samples were analyzed for the mass fraction of the solid phase, grain-size classification and viscosity. Static stability was determined by the presence of sediment and water separation during storage of the sample under static conditions. The mass fraction of the solid phase was determined by the standard drying method according to GOST 2731491, the grain-size classification was determined by wet sieving on sieves $0.355 \mathrm{~mm} ; 0.250$ $\mathrm{mm}$ and $0.071 \mathrm{~mm}$ according to GOST 2093-82, ash content - according to GOST 1102295.

Viscosity measurements were carried out on a RHEOTEST rotary viscometer in the shear rate range from 1.0 to $437.4 \mathrm{~s}-1$ with a standard S2 cylinder system. The measurement temperature was $20 \pm 5^{\circ} \mathrm{C}$ [13-15].

\subsubsection{Demineralization}

Preliminary demineralization of the initial coal raw material ensured effective removal of the mineral part of the coal raw material to obtain demineralized coal concentrate and coal-oil granulate, which is sent for preparation of organo-and-coal suspension, and mineral sediment, which was removed from the process, which reduces production costs and increases the mechanical reliability of the equipment used (cavitators, pumps and etc.).

The raw material was previously subjected to wet grinding to cl. $0-1(3) \mathrm{mm}$, followed by demineralization of the coal-water suspension by oil granulation to obtain a coal concentrate and a mineral solution, wherein an organo-and-coal suspension (OCS) prepared on the basis of the obtained coal concentrate was subjected to extreme physical influence. The use of a predominantly starting organic solvent as an oil agent leads to an increase in the efficiency of the degradation process of organic compounds.

The technological line, which implements the proposed method for the destruction of organic compounds of coal raw materials in an organic solvent by using extreme physical influences, contains: a unit for preliminary wet grinding of initial coal raw materials to class. 0-1 (3) mm, unit for mixing the coal-water suspension with the oil agent, unit for separating the formed coal-oil granules and separating the mixture of water and mineral compounds; a unit for dehydration of a mixture of water and mineral compounds; an installation for producing an organo-and-coal suspension based on coal concentrate - coal of oil granulate and an organic solvent, which is mainly used as an oil granulation agent; node of extreme physical effects, including zones of hydrodynamic and ultrasonic cavitation.

\section{Liquefaction of organic mass of coal}

Further, the process of liquefaction of the organic mass of coal in an organic solvent was carried out by exposing the initial mixture (coal + organic solvent) to extreme physical 
influences. Processes are necessary for deep processing of coal. The obtained coal-oil suspension was accumulated in a tank and then passed sequentially through a RPA-type cavitator pump, an IZAP-1/22-OP ultrasonic apparatus and a generator of high-frequency electromagnetic discharges. The treatment of the coal-oil suspension was carried out in this way for 20 minutes. After this treatment, the resulting liquid was analyzed for the yield of liquid fractions. After distillation of samples of the obtained product, the total yield of liquid fractions boiling up to $350^{\circ} \mathrm{C}$ was more than $90 \%$ in all samples obtained. In addition, under these conditions, more than $95 \%$ of the organic part of the coal was destroyed. The mineral residue was $1.5 \%$. Table 2 shows the yield of fractions boiling in temperature ranges. These tables show an increase in the amount of liquid fractions when applying cavitation affect on the processed mixture.

Table 2. Yield of fractions.

\begin{tabular}{|c|c|c|}
\hline Components & $\begin{array}{c}\text { Processing, } \\
\text { mass fraction } \%\end{array}$ & $\begin{array}{c}\text { Liquefaction result, } \\
\text { mass fraction \% }\end{array}$ \\
\hline $\begin{array}{c}\text { Petroleum product, } \\
\left(170-364^{\circ}\right)\end{array}$ & 16,8 & 33,5 \\
\hline $\begin{array}{c}\text { Petroleum product, } \\
\left.\text { (over } 364^{\circ} \mathrm{C}\right)\end{array}$ & 30,7 & 27,6 \\
\hline Total & 47,5 & 61,1 \\
\hline
\end{tabular}

\subsection{Liquefaction of the organic mass of coal in a cavitation unit with the addition of a hydrogen donor}

One of the most important areas of coal chemistry is the direct conversion of coal to organic products. For this purpose, the reactions are carried out so as to crack the selected bonds to obtain structural fragments of interest. The highly selective cracking of initial structures can lead to the formation of several valuable chemical intermediates or "precursors" of a number of certain commodity products.

Studies were conducted on the possibility of liquefaction of the organic mass of coal under the influence of cavitation phenomena arising in a cavitator with the addition of a hydrogen donor. The amount of additive ranged from 1 to $10 \%$ per dry organic mass of coal. A mixture of $60 \%$ cis-decaline and $40 \%$ trans-decaline, which is a bicyclic organic compound, was used as a hydrogen donor and used as a solvent for many resins or fuel additives. The figure shows the effect of the number of suspension processing cycles in the cavitator on the decrease in the solid phase in the suspension. 


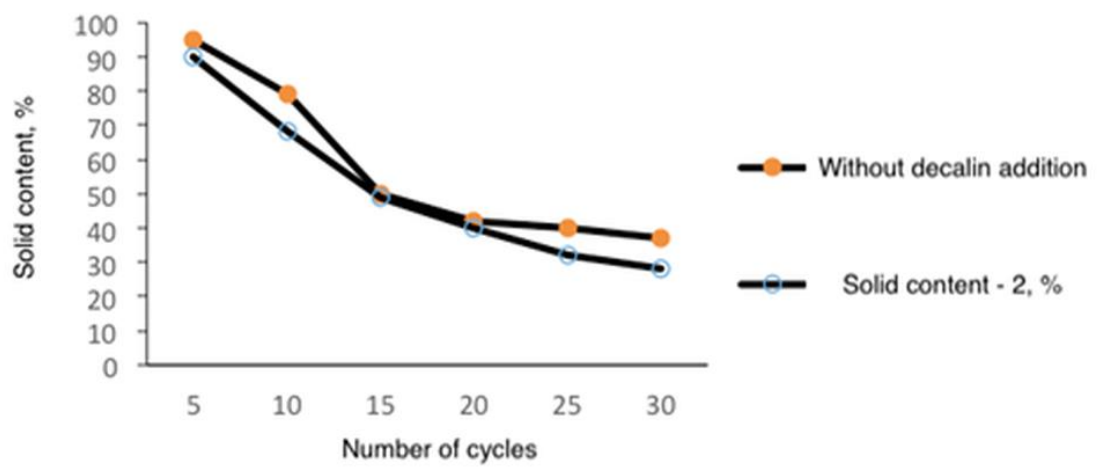

Fig. 1. Influence of the number of cycles of passing the suspension through the RPA on the liquefaction process.

Coal liquefaction products were analyzed by IR spectroscopy. The presence in the liquid phase of 5-methyltetralin and 6-methyltetralin, which are products of the cracking of organic substances of coal, are determined and are valuable chemical reagents. It should be noted that these chemical compounds can be formed during the transmethylation of decalin, a hydrogen donor, during the cracking of the structures of organic matter in coal.

\section{Results and discussion}

The technological and technical feasibility of deep processing of coal by its liquefaction using the methods of extreme mechanochemical and physical effects has been determined, recommendations are given for the applied use of the materials obtained in heat power engineering. The organic part of the solid mass of the prepared coal-oil suspension, which has turned into a relatively heavy organic liquid, can be used as a boiler or motor fuel, as well as a feedstock for the production of various hydrocarbon liquids. The resulting mixture of hydrocarbons can be subjected to rectification to obtain hydrocarbon fractions for the production of plastics, oil fractions and the entire spectrum of hydrocarbons for secondary use. The effective use of the above substances will allow to obtain not only economic, but also a significant environmental effect.

The technological and technical possibility of deep processing of coal by its liquefaction using the methods of extreme mechanochemical and physical effects has been determined; recommendations have been developed for the applied use of the obtained materials in heat power engineering. The organic part of the solid mass of the prepared coal-oil suspension, which has turned into a relatively heavy organic liquid, can be used as a boiler or motor fuel, as well as a feedstock for the production of various hydrocarbon liquids. The resulting mixture of hydrocarbons can be subjected to rectification to obtain hydrocarbon fractions for the production of plastics, oil fractions and the entire spectrum of hydrocarbons for secondary use. The effective use of the above substances will allow to obtain not only economic, but also a significant environmental effect.

The possibility of liquefying the organic mass of coal using decalin as a hydrogen donor is shown. It was found that the addition of $3 \%$ decalin improves the liquefaction process during cavitation treatment. Liquefaction of the organic mass of coal is accompanied by the cracking of the structures of macromolecules of organic substances of coal into aromatic fragments with a lower molecular mass, containing functional groups.

It should be noted that the developed technology will solve the problem of increasing the value of the final coal product, including by involving unused fine coal sludge into 
circulation.

The research was carried out with financial support from the Russian Foundation for Basic Research. Research project No. 20-43-420016 r_a

\section{References}

1. V.I. Murko, V.I. Fedyaev., H.L Aynetdinov, M.P. Baranova, The 17th ICPC, (2013)

2. Janiszewski J., Int. J. Solids and Struct. (2012)

3. Alaa M. Musalam and Abdel Fattah A. Qaraman. International Journal of Energy and Environmental Research, V. 4, 3 (2016)

4. T.M. Khrenkova, Mechanochemical activation of coals. M., ed. "Nedra" (1993)

5. Zh.K. Kairbekov, Zh.T. Eshova, Zh.K. Myltykbaeva, International Journal of Applied and Basic Research, 8 (2012)

6. T.V. Selivanova, Itakura Bulletin of the FEFU Engineering School. 1, 10 (2012)

7. Vernon L.W. // Fuel. V. 59 (1980)

8. N.C. Deno, K. Curry, A.D. Jones, R. Minard, et al. // eds. Copper B.R., Petrakins L. Chemistry and Physics of Coal Utilization. N.Y. : Amer. Inst. Phys. (1980)

9. B.N. Kuznetsov, T.G. Shendrik, M.L. Shchipko. et al. Deep processing of brown coal obtaining liquid fuels and carbon materials. Publishing house of the SB RAS (2012)

10. Coal of the world / ed. L.A. Puchkov. - M.: Gornaya Kniga, Coal of Eurasia. T. 3 (2013)

11. V.A. Mikheev, E.V. Vorsina, T.V. Moskalenko, Trends in the development of science and education, 33, 1 (2017)

12. M. Baranova, IOP Conf. Ser.: Mater. Sci. Eng. 704, 012015 (2019)

13. V.I. Murko, et al IOP Conf. Series: Earth and Environmental Science, 548, 052055, (2020)

14. V.I. Murko, et al. Science-intensive technologies for the development and use of mineral resources. From: SibGIU, 6 (2020)

15. V.I. Murko, et al Mining Science and Technology. DOI: 10.17073/2500-0632-2020-14-11 (2020) 